\title{
EXPRESIONES NARRATIVAS DE SUBJETIVIDADES SOCIALES DIVERSAS EN EL NOROESTE ANDINO ARGENTINO
}

\author{
NARRATIVE EXPRESSIONS OF DIVERSE SOCIAL SUBJECTIVITIES IN THE ANDEAN NORTHWEST OF \\ ARGENTINA
}

\author{
María Luisa Rubinelli* \\ mrubinelli2004@yahoo.com.ar
}

\begin{abstract}
RESUMEN: En este trabajo nos ocupamos de los modos en que la mujer "transgresora" es caracterizada por distintos sectores de la sociedad jujeña argentina. Por un lado en narrativas populares andinas referidas a casos de mulánimas o condenadas, entendemos que -si bien es sancionada por el incumplimiento de normas comunitarias- se posibilita su recuperación e inclusión en la comunidad. En tanto que en la representación que las elites de esa sociedad, partícipes en mayor o menor medida del pensamiento evolucionista-positivista de la época, la condición de la mujer pobre aparece sometida a sanciones de diferente carácter, siendo estigmatizada e institucionalizada por cuanto su recuperación solo sería posible en contextos de encierro y adiestramiento. Analizamos diferentes aspectos de los imaginarios sociales en juego.
\end{abstract}

PALABRAS CLAVE: Narrativa popular andina, Discursos institucionales, Mujer de sectores populares.

ABSTRACT: In this paper we are concerned with the ways in which the "transgressive" woman is characterized by different sectors of the Argentinean Jujeña society. On the one hand, in Andean popular narratives referring to cases of mulanima or condemned, we understand that - although it is sanctioned for non-compliance with community norms - it makes possible its recovery and inclusion in the community. While in the representation that the elites of that society, participants in a greater or lesser extent of the evolutionist-positivist thought of the time, the condition of the poor woman appears subject to sanctions of different character, being stigmatized and institutionalized because its recovery Would only be possible in contexts of confinement and training. We analyze different aspects of the social imaginaries at play.

KEYWORDS: Andean popular narrative, Institutional discourses, Woman popular sectors.

En la región andina, que la provincia de Jujuy, en el extremo noreste de Argentina integra, está vigente la creencia en la existencia de condenados, creencia que se trasmite a través del relato oral, que conserva importancia en la comunicación cotidiana.

Los relatos que narran casos de condenados se refieren a personas que, habiendo muerto, no puede descansar en paz, como el resto de los difuntos, y deben regresar al mundo de los vivos - al que ya no pertenecen - por el que vagan sufriendo. Este personaje tiene algunos rasgos que lo caracterizan y diferencian de otras almas en pena de la narrativa universal.

* Doctora en Filosofía y docente de la Universidad Nacional de Jujuy. 
Los condenados, según las creencias vigentes en la zona, son seres que no pueden integrarse al ciclo que cumplen los difuntos, debido a alguna falta cometida en contra de alguna norma vigente en su comunidad. Son seres transgresores que, por ello, han quedado al margen de la comunidad a que pertenecieron en vida.

Actualmente trabajamos en el desarrollo de un proyecto de investigación ${ }^{1}$ en que indagamos acerca de la construcción social de la realidad, desde la vida cotidiana entendida como construcción intersubjetiva, que problematizamos. Ubicamos la indagación en curso en las primeras décadas del siglo XX y las últimas del XIX, en la región andina y de valles del noroeste argentino.

Nos nutrimos de aportes de autores como Michel de Certeau, quien destaca la existencia de una red de conflictos ocultos en la cotidianidad, en relación con los que los sujetos, en tanto actores y autores en su historicidad cotidiana, crean un espacio utópico en que se afirma la posibilidad de resistencia y cambio a través de tácticas "populares" que no aguardan cambios rápidos, constituyéndose en una ética de la tenacidad.

También B. de Sousa Santos nos posibilita pensar en una sociología de la emergencia, a partir de una epistemología de las ausencias, que valora el conocimiento construido desde experiencias sociales, capaces de establecer una relación con el mundo a través de conocimientos que incluyan una dimensión utópica y liberadora. Denuncia la monocultura del saber; del tiempo lineal y el modelo evolucionista; la lógica de la naturalización de las diferencias, y de la escala dominante. La práctica de la traducción entre culturas - también promovida por R. Fornet Betancourt en el marco de la filosofía intercultural - posibilitaría crear inteligibilidad recíproca entre las experiencias del mundo disponibles y posibles, mientras que la epistemología de las ausencias promovería que las ausencias cobren significativa presencia, en consonancia con la identificación de las funciones de alusión- ilusión y elusión discursivas planteadas por A. A. Roig en su desarrollo de la categoría de universo discursivo.

Con Silvia Rivera Cusicanqui recuperamos el principio del tercero incluido, en este caso propuesto para la interpretación del pensamiento andino, a través de la categoría de ch'ixi (término aymara) como "sociedad abigarrada", o coexistencia en paralelo de múltiples

\footnotetext{
1 "La subjetividad y su constitución en la tensión individualismo y colectividades "abigarradas" Entre sujeto nacional homogéneo y abirragamiento multiculticutural, en Jujuy (1880-1935)". Secretaría de Ciencia, Técnica y Estudios Regionales. Universidad Nacional de Jujuy. Argentina.
} 
diferencias culturales que no se funden, sino que antagonizan o se complementan. Cada una se reproduce a sí misma desde la profundidad del pasado y se relaciona con las otras de forma contenciosa" (2010, p. 70). Se trata de una categoría propuesta por Zavaleta Mercado para la interpretación de la complejidad de la sociedad boliviana.

No es objetivo de nuestro proyecto indagar solo las representaciones sociales de sectores de elites, que son los que habitualmente quedan registrados mediante la escritura o la imagen y su continua reiteración por parte de instituciones del Estado, como la escuela, y forman parte de una versión oficial de la historia. Por ello buscamos abrevar en otras fuentes, como las publicaciones periodísticas, la narrativa popular, los cancioneros, los rituales, los procesos judiciales entre otras.

Las llamadas mulánimas o alma mula son una variante de condenados, que se originan en metamorfosis sufridas por mujeres transgresoras de normas del grupo comunitario referidas a prácticas sexuales. Las transgresiones que determinan la transformación de la mujer en mulánima son, según las versiones recogidas, no haber querido tener hijos pudiendo hacerlo, haber mantenido relaciones incestuosas con hermanos, padres, compadres, hijos, o con un sacerdote.

Quien se condena de esta manera es siempre la mujer, que adquiere una apariencia monstruosa y temible que aterroriza. La transformación puede ocurrir antes o después de la muerte de la transgresora. En el primer caso, tiene la oportunidad de pedir perdón por el adulterio cometido y de continuar su vida matrimonial, quedando convertida en mujer normal, si es perdonada por el afectado. Si se trata de alguien ya fallecida y condenada, al ser liberada puede - a partir de ese momento - reintegrarse en paz - como difunta -, a la vida de su comunidad. Es la contraparte femenina del personaje masculino condenado por haber mantenido relaciones incestuosas, caso menos frecuente.

Es importante tener en cuenta que en la concepción andina los difuntos no parten hacia un más allá sin relación con el mundo de los vivos. En el transcurso del tiempo cíclico anual, está previsto un período de encuentro y convivencia entre vivos y difuntos, que se celebra mediante complejos rituales a principios de noviembre. Si bien en nuestra región ese encuentro dura pocos días, según estudios realizados por Bouysse Cassagne y Harris en comunidades aymaras bolivianas, se prolongaría entre principios de noviembre y la culminación del carnaval, cada año. Durante ese período, mediante la participación en los rituales, se afianzan los lazos entre los vivientes y de éstos con los difuntos, que siguen 
siendo miembros de la comunidad, a la que aportan su energía en las actividades vinculadas a las siembras, cosechas, cuidados del ganado y, en general, reproducción de la vida.

La mulánima parece seguir dos estrategias diferentes, según se trate de una mujer que aún vive o que haya fallecido. En el primer caso cada noche recorre el camino hacia la iglesia, donde habita el co-responsable de su condena, si sus relaciones fueron con un sacerdote. En cambio, cuando se trata de alguien que ya murió y se condenó, sus recorridos parecen tener como propósito hallar a quien sea capaz de liberarla. Cuando no lo encuentra, se enfurece. Rebuznos y llantos son los únicos sonidos que parece poder emitir la mulánima. No hay otro lenguaje que pueda emplear para comunicarse con los demás, lo que confirma su carácter no humano. En ella aparece un rasgo presente en otros tipos de condenados: la antropofagia.

Pero la responsabilidad de la relación incestuosa no es la única transgresión causante de transformación de la mujer en mula, ya que también le ocurre a aquella que pudiendo hacerlo - no ha tenido descendencia. Su infertilidad quedará reforzada, en tanto como mulánima - será un híbrido incapaz de reproducirse. Teniendo en cuenta que la unidad de producción en el mundo andino es la familia, la suya aparece como una conducta contraria a la reproducción de la vida.

Nos concentraremos en las mulánimas que penan luego de ocurrida su muerte. Aparecen cuando oscurece, en noches no alumbradas por la luz de la luna, a veces en medio de tormentas. Como indicios de la condena portan freno y cadenas, a modo de reproducción invertida de aquello cuya importancia ha sido concientemente desconocida y negada: las normas sociales que reglamentan la sexualidad permitida. Luego de la muerte son expresión de la prohibición de la partida, en tanto la transgresión cometida ha generado una deuda con el mundo de los vivos que se hace explícita, y que no puede ser ignorada sino saldada en el mundo de los vivientes, antes de poder abandonarlo. La condenada, como todos los seres de esas características, se encuentra en soledad, impedida de cualquier relación tanto con vivientes como con otros difuntos. El aislamiento individual es una situación penosa por inconcebible en un mundo profundamente relacional como es el andino, en que todos los seres existen vinculados entre sí.

Como en otros relatos, se destaca el personaje del sacerdote. Aquí - en general co-partícipe y co-responsable de la relación incestuosa. Morote Best afirma que en algunas regiones del Perú también el cura se transforma. En relación con la participación de 
sacerdotes en acciones reñidas con las normas sociales, se registran numerosos casos de quebrantamiento de sus votos, ya que mantienen relaciones sexuales con feligresas, roban, mienten, profanan tumbas, acumulan riquezas, atentan contra la vida de supuestos protegidos. La figura del sacerdote como personaje de relatos reconoce gran antigüedad en la región andina. Mientras desde la legislación y la burocracia españolas se instala el rol del "protector de indios", desde la vida cotidiana se destacan como actores importantes en la ejecución de las formas de sometimiento de las comunidades" (MADRAZO, 1982, p. 89).

En el siglo XVII, según Duviols, entre algunas de las principales acusaciones que realizan los indios contra los visitadores de idolatrías (DUVIOLS, 1977, p. 402), se destacan: el sometimiento de indias solteras a abusos sexuales, la explotación de tejedores y tejedoras a escala industrial.

Silverblatt, acudiendo al testimonio de Guaman Poma, sostiene que

los curas eran los más viciosos perpetradores de la deshumanización de la mujer (...) las obligaban a servir como trabajadoras, amantes y prostitutas (...) Al depender de los españoles y de sus colaboradores, la mayor parte (...) no tuvo otra opción que participar en su propia degradación. (SILVERBLATT, 1990, p. 103, 107)

Los relatos sobre mulánimas que hemos analizado datan de las primeras décadas del siglo XX, aunque algunos son de nuestros días.

A comienzos del siglo XX Argentina se encuentra en pleno proceso de organización nacional, en que los principios de orden y progreso se asientan en la necesidad de construcción de una sociedad fuertemente jerarquizada y sometida a la hegemonía de sectores oligárquicos que instrumentarán un sistema de aprovechamiento de mano de obra de bajo costo, sea proveniente de poblaciones indígenas sometidas o de migrantes, y proyectarán un sistema de control centralizado sobre los sectores populares, ya que la constitución de la nación estará ligada al control social y al disciplinamiento de los sectores sociales más desfavorecidos, a ser adiestrados como fuerza de trabajo.

Muchos intelectuales y personalidades políticas de la época, con espíritu acorde al desarrollo de las teorías evolucionistas y darwinistas, consideran demostrado por la ciencia y la observación que la mujer, por naturaleza, está especialmente dotada para el sentimiento, para ejercer la maternidad y la función de esposa, siendo el sostén de la familia monogámica. Por ello entienden que debe abstenerse de incursionar en el conocimiento 
científico, el comercio, la industria, la política, campos en que prevén su fracaso, por estar reservados exclusivamente al hombre.

Villafañe, político jujeño de la época dirá que las mujeres que intentan incursionar en los dominios reservados al varón son seres descentrados, condenados a sufrir las consecuencias de una labor para la que no las preparó la naturaleza, desatendiendo el destino que Dios les asignó: ser esposas, madres, ejes del hogar sano. Según B. Villafañe, ${ }^{2}$ la mujer en el pasado argentino ha sido el sostén del "viejo hogar castellano, síntesis de todas las virtudes" (VILLAFAÑE, 1936, p. 84) al que caracteriza como salvaguarda de la identidad nacional (VILLAFAÑE, 1937, p. 37), refugio de argentinidad que localiza en el interior del País, en que la educación y conducta austeras de sus pobladores se oponen a la frivolidad y confort de las grandes ciudades, entonces en franco y desordenado crecimiento por la masiva llegada de migrantes. Este autor sostiene que la mujer, "heredera de las virtudes de las de la Conquista y de la Revolución (...) ser superior al hombre (...) en belleza física y moral; superior en la resistencia al dolor, en el amor a la patria y a la libertad (...) templo que guarda el secreto de la vida (...) [ lleva] en su seno a Dios mismo" (VILLAFAÑE, 1953, p. 9 y 72). Cuerpo y cerebro de la mujer han sido modelados por Dios para la tiranía del amor de esposa fiel y madre, vida del hogar, célula primera de la sociedad. El matrimonio cumplía la "función de protección de la propiedad privada, con el predominio de hombres (padres) sobre las mujeres (solteras o casadas) y los hijos legítimos" (ANSALDI Y GIORDANO, 2012, p. 377).

Pero, mientras Villafañe rechaza, amparándose en fundamentos éticos y religiosos, la legitimidad de movimientos que reivindican - en esa época - la participación de la mujer en el desempeño de distintos roles sociales y políticos, A. Álvarez, otro pensador positivista de la época apoya el advenimiento de la mujer a la esfera pública, y se pronuncia en defensa de sus derechos. Tal como sostiene Ramaglia, "si bien el positivismo logra una cierta hegemonía respecto a otras corrientes [de pensamiento] no representa al igual que en otros países latinoamericanos una ideología adoptada en forma oficial” (RAMAGLIA, 1998, p. 11), como tampoco implica el desarrollo de una doctrina monolítica, sin variaciones y contradicciones a su interior.

\footnotetext{
${ }^{2}$ Miembro de la elite de la época, que desempeñó numerosas funciones políticas, tanto a nivel provincial como nacional.
} 
Arturo A. Roig estudia la corriente krauso- positivista, que se desarrolla en la época, en la que ubica el pensamiento del pedagogo Vergara, quien argumenta a favor de la educación conjunta de ambos sexos y coloca a la mujer en igualdad de condiciones con el hombre.

Villafañe - a pesar de sus ideas positivistas y en consonancia con las características conservadoras de la elite jujeña - adhiere a la religión católica tradicional, a la que considera salvaguarda de la moralidad pública. ${ }^{3}$

Roig destaca que el positivismo argentino fue optimista. "Tenían fe (...) nuestros positivistas en la patria, en la humanidad, en la ciencia y en la educación (...) Lucharon contra el descreimiento y la inmoralidad dando cuerpo a un eticismo tan fuerte como el (...) krausista, si bien con diverso signo." (ROIG, 2006, p. 63)

La concepción de educación que expresa Villafañe en esa época, tiende en cambio a la "domesticación", a la adaptación a las "buenas costumbres", entendidas como orden social correcto.

En los circuitos de control establecidos desde el Estado por los sectores dominantes, algunas instituciones ejercieron destacado papel de disciplinamiento. Una de ellas fue la escuela, ejerciendo su mandato civilizatorio y homogeneizador. Otras: la Policía, que controlaba la posibilidad de circulación de las personas pobres, permitida a partir de su efectiva dependencia de un empleador, verificada mediante la presentación de la "papeleta de conchavo"; ${ }^{4}$ el sistema de salud con la exclusión social o la internación de enfermos, según los casos, y el enclaustramiento de menores indigentes, así como el desarrollo de mecanismos de control para la prevención de epidemias aclarar; las sociedades de "beneficencia pública" ocupadas de diseñar e instrumentar estrategias de control de las costumbres de los sectores marginados así como de la implementación de acciones asistenciales; la cárcel pública; y específicamente para el tratamiento del "problema" de la

\footnotetext{
${ }^{3}$ Se entiende por moral pública el conjunto de "obligaciones que regulan ciertos vínculos sociales, sin sanción jurídica (...) Todas las acciones relacionadas con la ética, en función (...) de la convivencia (...) Pretende establecer relaciones de respeto y armonía en una sociedad" (MALLAGRAY, 2009: 36).

${ }^{4}$ Jujuy, Ley 477 (16/12/1895) Art. 2: "En presencia de un patrón y de aquel cuyo servicio se contrataren extenderá el funcionario un certificado o papeleta correspondiente haciendo constar la fecha de expedición, el nombre de ambos contratantes, el plazo del servicio y el salario o sueldo convenido.

Art. 4: Todo individuo de ambos sexos mayor de 18 años que no posea bienes sujetos a contribución o que no ejerza profesaba, arte o industria que asegure su subsistencia, está obligado a muñirse de la respectiva papeletea que acredite su conchavo".
} 
mujer pobre, menores abandonadas, delincuentes y prostitutas, el Instituto del Buen Pastor, que basaba su estrategia de "rehabilitación" de la mujer mediante el castigo, la educación cristiana y la capacitación para el servicio doméstico.

El Asilo Maternal acogía a niños de familias pobres. El sistema judicial contaba con la figura de la tutela dativa que, mediante intervención del Ministerio de Menores, permitía la colocación de niños y niñas ("chinitas", "criaditas") bajo tutela de familias "decentes"5 que aprovechaban los beneficios de la mano de obra (barata o gratuita) para servicios domésticos, como contraparte de la protección, formación cristiana, comida y vivienda brindadas, compromisos en numerosos casos incumplidos.

Ingenieros, a principios del (...) XX (...) definía el delito como (...) transgresión a las limitaciones impuestas por la sociedad (93) al individuo en la lucha por la existencia como un fenómeno al mismo tiempo biológico, psicológico y social; sostenía que (...) el ambiente físico como el social influían en la configuración del carácter y comportamiento del delincuente ... Al amparo de estas reglas, muchos "inadaptados sociales" como locos, mendigos, alcohólicos (...) resultaron "delincuentes" y (...) punibles de encierro" (cit. por MALLAGRAY, 2009, p. 93).

Si bien en la propuesta de Ingenieros se predicaba la rehabilitación del preso y su disciplinamiento en el trabajo productivo, entendido como derecho y como forma de reinserción social, las precarias e indignas condiciones reales de vida en las instituciones carcelarias no hicieron posible su concreción. En todas esas instituciones subyace el propósito de formación de mano de obra disciplinada.

Entendiendo que "la mujer (...) está constantemente expuesta a crisis que comprometen (...) sus facultades intelectuales" (PIÑEIRO, 1888, Apud: MALLAGRAY, 2009, p. 151), se concebía que podría salvaguardar su decencia y honestidad solo sometida a la autoridad masculina. En el caso de la mujer indígena el problema se agravaba, dado que carecen de "noción alguna de moral (...) [En ellas] el pudor, dignidad y honor son inexistentes" (Archivo de Tribunales de Jujuy, Leg. № 190, 1898, Apud: MALLAGRAY, 2009, p. 155).

El discurso oficial, reiterado ya sea desde la autoridad del Estado o de la Iglesia católica, enfatiza la función maternal de la mujer que, validada por la ciencia como hecho

\footnotetext{
${ }^{5}$ Categoría proveniente del orden colonial, en que designaba a quienes eran situados en el vértice social superior (ANSALDI y GIORDANO, 2012, p. 401)
} 
biológico, legitima un ideal de hogar en que ella debe ser eje de la formación moral de los niños.

Teniendo en cuenta lo dicho, podríamos sostener que la narrativa con la que comenzamos sería expresión de la influencia ejercida por la ideología de las elites sobre los sectores populares que, de esa manera, la reproducirían acríticamente, internalizando las normas reguladoras de la sexualidad femenina conforme a las "buenas costumbres" pregonadas por las familias burguesas.

Sin embargo, en la concepción popular andina, la condena sufrida por la mujer incestuosa es - la absoluta mayoría de las veces - transitoria, ya que la mulánima puede liberarse si alguien, en general un hombre, quiere, intenta y logra quitarle el freno. No hemos hallado ninguna versión que considere la idea de un castigo eterno, que impida a la mulánima - bajo las condiciones mencionadas - liberarse. La reciprocidad (en este caso entre vivos y difuntos, pero siempre presente como forma de relación en el pensamiento andino) ejercida por quien, sea o no miembro de la comunidad, arriesga su vida hasta el límite de poder perderla, para salvar a la condenada, posibilita la reinserción social de la mujer.

Las lógicas puestas en juego en ambas concepciones son diferentes. Mientras la que se hace presente en los relatos sobre mulánimas es de liberación y de inclusión, y es procurada activamente por la condenada, que sufre hasta lograrla; la de rehabilitación planteada desde la visión de las elites es de castigo y reclusión de una mujer que, concebida como un ser pasivo, debe sujetarse al dominio masculino, no para liberarse sino para someterse a su rol en una sociedad encorsetada en la lógica del poder, que la encierra o la excluye al considerarla peligrosa para su subsistencia.

Las ideas de Villafañe acerca de la educación requerida por el país en ese momento de su historia, se explicitan a través de sus críticas a la educación secundaria, que entiende forma para desempeñar funciones burocráticas, no productivas, siendo éstas las únicas capaces de fomentar el progreso del País. Así, la juventud prefiere cursar carreras universitarias como consecuencia de la errónea creencia de la igualdad entre los hombres. Pero el cultivo de las ciencias está destinado solo a los cerebros mejor dotados, lo que es sostenido aún luego de haber acontecido la Reforma Universitaria de 1918, que irradió su influencia en toda Latinoamérica. También Ingenieros califica de erróneo el ideal de igualdad entre los hombres ya que, sostiene, 
la heterogeneidad es natural, por las diferencias de aptitudes y de tendencias humanas, y es provechosa, porque engendra las desigualdades necesarias para las múltiples funciones de la vida social. Siendo naturales, las desigualdades no pueden suprimirse, ni convendría suprimirlas (...) La solidaridad consiste en equilibrarlas, creando la igualdad ante el derecho, para que todas las desigualdades puedan desenvolverse íntegramente en beneficio de la sociedad" (INGENIEROS, 1991, p. 38).

Pero, al menos en esta obra, concibe esa desigualdad en términos de diversidad valiosa para el conjunto.

"La mujer (...) siendo un ser sensible y sublime, no apta para la lucha por la vida, deberá ser educada en la virtudes que favorezcan el desempeño de la función materna que le es propia. Como diría Félix Frías, evitando 'las excentricidades de la imaginación y (...) [respetando] la naturaleza y simplicidad femenina.'” (Apud: MALLAGRAY, 2009, p. 47).

Así, "la mujer es considerada una amenaza real, mientras en el plano ideal es encumbrada como madre de la patria" (ANSALDI y GIORDANO, 2012, p. 478). La figura de la mujer-madre emerge en la representación de la patria como "madre que nos nutre, que nos fortalece, sonrisa de Dios en pupilas de mujer" (VILLAFAÑE, 1936, p. 54).

Si se trata de mujeres humildes, de hogares obreros o campesinos, a fin de que no caigan en el vicio y cuiden su dignidad, se sostiene la necesidad de que se eduquen en escuelas profesionales o de oficios, que serían así útiles instrumentos para afrontar el problema de la cultura de los bajos fondos (VILLAFAÑE, 1922, p. 351-352). Nuevamente, una formación que capacite mano de obra de bajo costo para la industria, el comercio y la explotación agrícola- ganadera, así como para el servicio doméstico.

La concepción moral en que debían formarse los niños y los sectores populares estaba unida e influida por la importancia asignada a la enseñanza y práctica de la higiene y a los conocimientos prácticos.

A los maestros se confiaba la enseñanza del dominio de las pasiones. Los sectores conservadores temían que, habiendo sido abolida la enseñanza religiosa que concebían directamente relacionada con la vigencia de la moral, la fuerza del populacho, no sujeta a límites, desbordara todo orden social. Por ello, los maestros debían educar en el amor a la ciencia, la justicia y el bien, teniendo en cuenta los valores de Patria, Dios, familia y propiedad, considerados pilares básicos de la organización social.

En contraste con la concepción expuesta, Vergara lejos de considerar al niño como ser poco evolucionado, lo entiende como capaz de tomar decisiones y de desarrollar su 
aprendizaje en libertad, con escasa intervención del docente, para ir logrando creciente autonomía como persona y como ciudadano de una república, para lo que es necesario desterrar las prácticas políticas corruptas y opresivas de los sectores dominantes. La autonomía va unida a la solidaridad y el respeto de "las diversas y múltiples energías naturales y humanas" (VERGARA, 1916, p. 448).

Puiggrós y Roig, entre otros, consideran a Vergara representante de la corriente pedagógica innovadora imbuida de ideas krausistas, que comparte la preocupación por temas de gran significatividad en la época, tales como la importancia de la formación moral del individuo y de la sociedad, lo que cimentaría el progreso de la nación. También en esta vertiente del pensamiento se encuentra siempre presente la analogía del proceso natural, biológico, con el social. Los seres de la naturaleza como los seres humanos y las sociedades lograrán concretar sus mejores potencialidades, en beneficio del conjunto, si desde las instituciones - en especial las educativas - se fomenta el libre desarrollo de sus iniciativas. Vergara afirma que "cada ser organizado encarna un plan divino preparado desde millones de años por la mano de Dios mismo" (VERGARA, 1916, p. 433). Con ello presenta una concepción profundamente religiosa de la vida y nos muestra la impronta decisiva en su pensamiento de la idea de evolución universal. Sin embargo, desde su posicionamiento liberal considera que la formación moral se sustentará en una enseñanza que acreciente la libertad y las posibilidades de acción solidaria para el bien. El liberalismo personalista argentino proclama la solidaridad como fundamento de la política, por lo que este principio adquiere sentido "a la vez jurídico, sociológico y religioso." (ROIG, 2006, p. 70)

En el pensamiento de Vergara, en tanto el proceso educativo trasciende a la institución escolar hacia la sociedad misma y la vida cotidiana, el docente tendrá como misión brindar un ambiente adecuado para que el estudiante aprenda por sí solo, haciendo, trabajando, consultando libros de su interés. Las instituciones deben poder tomar decisiones, fomentando la amplia participación del pueblo en su interior. Promueve entonces el respeto de la diversidad de iniciativas que surjan como respuesta a las necesidades de cada localidad. Así, "la escuela tendrá como misión (...) alcanzar una referencia a la unidad, pero desde un complejo heterogéneo siempre diferente" (ROIG, 2006, p. 159). 
En Jujuy, Pablo Arroyo aparece como un referente de ideas pedagógicas krausistas. Puiggrós sostiene que "educadores inspirados en ideas democráticas y antinormalizadoras, con mayor o menor apoyo teórico, más o menos influidos por el krausismo o por el pragmatismo, [han] surgido la mayor parte de las veces de la lucha pedagógica en escuelas del interior del país" (PUIGGRÓS, 1996, p. 8). En tanto Roig afirma que el krausismo no constituyó una escuela, sino que fue obra de pedagogos y políticos que actuaron en forma (...) individual y aislada, si bien ejercieron (...) influencia" (ROIG, 2006, p. 18).

Los seguidores del pensamiento evolucionista, consideran a los sectores sociales "humildes" (y entre ellos a los indígenas) como seres que no poseen un nivel de entendimiento superior al de un niño, por lo que sería desatinado pretender alimentar sus cerebros con conocimientos destinados a seres desarrollados, ya que sobrecargarlos con acumulación de conocimientos para los que no son aptos, contribuye a producir anormalidades. Es necesario formarlos para el trabajo productivo y asalariado, así como en estrictos hábitos de higiene.

“Los higienistas primero -como más tarde los criminólogos positivistas- (...) [bogaron] por una legislación que amparara sus procedimientos imbuidos del discurso de la "defensa social" (MALLAGRAY, 2009, p. 40). Siendo considerados como peligrosos y portadores de amenaza a la pulcritud del orden social, los sectores populares debían ser severamente disciplinados, a lo cual contribuían el trabajo y la higiene.

"La miseria, el hambre, la enfermedad, la mendicidad y la indigencia en sus distintas formas fueron (...) situaciones que las elites contemplaron como (...) amenaza al orden social establecido. La pobreza fue relacionada (...) con el desorden (...) de la moral pública" (MALLAGRAY, 2009, p. 35). Por ello reclamaban la implementación de estrategias asistenciales que, atendiendo las necesidades de los más desprotegidos, fortalecieran el modelo social desarrollado por el proyecto liberal.

Pero desde la segunda mitad del siglo XIX las ciudades, en descontrolado proceso de crecimiento como consecuencia de la llegada de contingentes de migrantes que se afincaban en ellas, estuvieron expuestas a continuos brotes de epidemias, que implicaban un grave peligro para todas las clases sociales. El discurso y la autoridad médica se impusieron como salvaguardas de la vida, y las instituciones de control se desarrollaron no solo por iniciativa 
estatal, sino en colaboración con sectores de las elites, y así la Sociedad de Beneficencia se constituyó en arquetipo de institución de ayuda social.

Otra cuestión que en época de organización de la nación y de su sistema educativo concita interés, es la tensión entre centralización/ descentralización, en un país que se proclama republicano y federal. La civilización aparece siempre en contraste con su opuesto, según la tradición sarmientina: la barbarie, atribuida a los indígenas en general, adoptando como estereotipo de los mismos a los pueblos originarios de las pampas, amalgamados con el desierto, en las antípodas del ideal de productividad del modelo liberal.

Al respecto sostiene Bengoa que surge en la ideología criolla la "tesis de la raza decadente". Así,

la imagen española de una raza indígena fuerte, de grandes civilizaciones llenas de oro (...) pasa a dar lugar a la idea criolla de que si antes los indios eran valientes, sabios, ricos, hoy son pobres, flojos, adormecidos, embrutecidos y raza decadente (...) [que] se debaten en la desesperación de la pobreza, del alcohol, de la falta de dignidad y señorío. Esa (...) teoría de la decadencia (...) acompañará por siglos las ideas comunes sobre los indios que tienen las clases criollas de nuestros países" (BENGOA, 2007, p. 169170),

legitimando la premisa de la necesidad de su sometimiento a la sociedad civilizada, del no reconocimiento de derechos y de la desposesión de los territorios históricamente habitados por ellos. Así, "la idea de inferioridad, de primitivismo, de barbarie" va a sostener las relaciones interétnicas en América Latina (BENGOA, 2007, p. 194).

Sin embargo, los indígenas de las tierras altas (QUEBRADA y PUNA) de Jujuy, son románticamente evocados por Villafañe como luchadores en pos de la independencia de la Patria. Siendo sedentarios y productores, en calidad de arrendatarios, generarían riquezas en zonas que, por sus rigurosas condiciones, imposibilitan la radicación de mano de obra extraña a ella.

En general, los positivistas comparten la convicción de que los indígenas presentan un grado de evolución superado con el advenimiento la modernidad liberal y el consiguiente desarrollo del conocimiento científico, y que por ello están predestinados a extinguirse. Ello es expresado sin rodeos por Spegazzini: “Ante la civilización que adelanta a pasos de gigante, los salvajes están condenados a desaparecer, y esto va a suceder entre pocos años, y los 
indios quedarán como recuerdos y leyendas; es indudable y fatal" (Apud: MASES, 2010, p. 78 - Bs.As., 1882).

Ese discurso fue exitoso en imponer la primacía de las ciencias naturales y la clasificación y jerarquización de los hombres. Las élites políticas e intelectuales, asumidas como blancas, definieron al otro como problema: "problema indígena", negro, inmigrante. (ANSALDI y GIORDANO, 2012, p. 544). Desde allí se construyó una ideología racialista oligárquica, que proyectó su discurso sobre la sociedad y se hizo sentido común.

Ansaldi y Giordano mencionan como presupuestos de esa doctrina los siguientes postulados: existencia de razas con preeminencia de unas sobre otras, continuidad entre lo físico y lo moral, determinación de la biología sobre la cultura, acción del grupo sobre el individuo, jerarquía única y etnocéntrica de valores, planificación política fundada en el saber acumulado por una minoría evolucionada, en consonancia con lo descripto. Será entonces fundamental disponer de un sistema de control social, a fin de asegurar la reproducción de ese orden logrado, unido estrechamente a la posibilidad de progreso.

El conocimiento médico se impone como matriz científica de comprensión de la sociedad, y disciplinador de la misma, asegurando su salud, por cuanto quienes actúen contra ese orden serán vistos como agentes patológicos a los que es preciso neutralizar.

En tanto se valora la capacidad de Argentina para posicionarse en el mercado mundial como agro productora, parte de la oligarquía jujeña sostiene la necesidad de la industrialización y diversificación productiva del País. Promueve la conjunción de esfuerzos de las provincias del Noroeste argentino, en pos del desarrollo de sus intereses económicopolíticos por el progreso de la región, tratando de poner freno a lo que caracteriza como la macrocefalia padecida por el País, en beneficio de la pampa y el litoral.

De lo dicho surge la diversidad de perspectivas convivientes en las sociedades jujeña y nacional de la época, fuertemente marcadas por las desigualdades sociales y el conservadurismo de los sectores oligárquicos dominantes que sentían peligrar su futuro ante el avance de concepciones republicanas más democráticas, surgidas de su propia fragmentación interna. Dentro de ese panorama nos interesa destacar las estrategias desarrolladas por sectores descalificados por aquéllos, que a través de la narrativa logran expresar concepciones alternativas en que aparecen valorados principios que aportan al 
desarrollo de concepciones ético-políticas más inclusivas, y su proyección en la sociedad actual, en que continúan siendo naturalizados el mandato civilizatorio de los sectores dominantes por un lado y el ocultamiento de los aportes de las culturas populares -en nuestro caso especialmente de las herederas de culturas indígenas- que persisten ofreciendo concepciones y prácticas alternativas.

\section{BIBLIOGRAFÍA}

ANSALDI, W.; GIORDANO, V. América Latina. La construcción del orden. T. I. Bs.As. Ariel, 2012.

BENGOA, J. La emergencia indígena en América Latina. Santiago de Chile: FCE, 2007.

BIAGINI, H. (comp.). El movimiento positivista argentino. Bs.As. Editorial de Belgrano, 1985.

BOUYSSE CASSAGNE, T.; HARRIS, O. et al. El concepto de pacha. In: BOUYSSE CASSAGNE, T; HARRIS, O. et all, Tres reflexiones sobre pensamiento andino. La Paz: Hisbol.

DUVIOLS, P. La destrucción de las religiones andinas. México: UNAM, 1977.

INGENIEROS, J. Las fuerzas morales. Buenos Aires: Siglo veinte, 1991.

MADRAZO, G. B. Hacienda y encomienda en los Andes. Buenos Aires: Fondo Editorial, 1982.

MALLAGRAY, L. Heridas por la vida. Huérfanas, prostitutas y delincuente. Control, disciplinamiento e integración social en Jujuy (1880-1920).SSJ. EdiUnju, 2009.

MASES, E. H. Estado y cuestión indígena. El destino final de los indios sometidos en el Sur del territorio (1878-1930). Bs. As. Prometeo, 2010.

PIÑEIRO, E. Creyentes, herejes y arribistas. El radicalismo en la encrucijada 1924-1943. Rosario: Prohistoria, 2014.

PUIGGRÓS, A. Historia de la educación en la Argentina. I. Bs.As. Galerna. 3a.. ed., 1996.

RAMAGLIA, D. El pasado y el presente. Antología de Agustín Álvarez. Mendoza: Ed. Culturales de Mendoza, 1998.

ROCABADO, M. Dulces, buenas y putas. Sexo bajo control en Jujuy (1890-1930).Buenos Aires: Purmamarka Ed. 3a. ed., 2016.

ROIG, A. A. Los krausistas argentinos. Bs. As. Ed. El Andariego. 2a . Ed, 2006.

RUBINELLI, M. L. Los relatos populares andinos. Expresión de conflictos. Bs.As. Biblos. 2å. ed., 2014.

SILVERBLATT, I. Luna, sol y brujas. Cusco: Centro de Estudios Regionales Andinos, 1990.

TERIGI, F.; ARATA, N. Vergara, C.N. Pedagogía y revolución. Escritos escogidos. La Plata: UNIPE, 2011.

VERGARA, C.N. (1916). Filosofía de la educación. Bs. As. Cía Sudamericana de Billetes de Banco. 
VILLAFAÑE, B. Irigoyen, el último dictador. Jujuy: Moro Tello \& Cía, 1922.

. La Ley suicida. Bs.As. Impr. Mercatali, 1936.

. Chusmocracia. Bs.As. Impr. Mercatali, 1937.

1953.

. Las mujeres de antaño. En el Norte argentino. Bs.As. Talleres Gráficos de Domingo E. Taladriz,

YEPEZ, D. E. Confrontación entre Estado e Iglesia. Sanción de la Ley 1420 y la rebelión antilaicista. In: SANTAMARÍA, D. (comp.). Jujuy: arqueología, historia, economía, sociedad. Jujuy: Cuadernos del duende, 2005. 